\title{
The ethics of Canadian entry-to-practice pain competencies: How are we doing?
}

\author{
Judy Watt-Watson RN MSc PhD' , Elizabeth Peter PhD BA MScN BScN ${ }^{1}$, A John Clark MD FRCP2, Anne Dewar RN PhD ${ }^{3}$, \\ Thomas Hadjistavropoulos PhD ABPP FCAHS ${ }^{4}$, Pat Morley-Forster MD FRCPC ${ }^{5}$, Christine O'Leary MN RN PNP6, \\ Lalitha Raman-Wilms BSc(Phm) PharmD FCSHP7 , Anita Unruh PhD MSW OT(C)RegNS², Karen Webber MN RN, \\ Marsha Campbell-Yeo RN MN NNP-BC PhD ${ }^{9}$
}

\begin{abstract}
J Watt-Watson, E Peter, AJ Clark, et al. The ethics of Canadian entry-to-practice pain competencies: How are we doing? Pain Res Manag 2013;18(1):25-32.

BACKGROUND: Although unrelieved pain continues to represent a significant problem, prelicensure educational programs tend to include little content related to pain. Standards for professional competence strongly influence curricula and have the potential to ensure that health science students have the knowledge and skill to manage pain in a way that also allows them to meet professional ethical standards.

OBJECTIVES: To perform a systematic, comprehensive examination to determine the entry-to-practice competencies related to pain required for Canadian health science and veterinary students, and to examine how the presence and absence of pain competencies relate to key competencies of an ethical nature.

METHODS: Entry-to-practice competency requirements related to pain knowledge, skill and judgment were surveyed from national, provincial and territorial documents for dentistry, medicine, nursing, pharmacy, occupational therapy, physiotherapy, psychology and veterinary medicine.

RESULTS: Dentistry included two and nursing included nine specific pain competencies. No references to competencies related to pain were found in the remaining health science documents. In contrast, the national competency requirements for veterinary medicine, surveyed as a comparison, included nine pain competencies. All documents included competencies pertaining to ethics.

CONCLUSIONS: The lack of competencies related to pain has implications for advancing skillful and ethical practice. The lack of attention to pain competencies limits the capacity of health care professionals to alleviate suffering, foster autonomy and use resources justly. Influencing professional bodies to increase the number of required entry-to-practice pain competencies may ultimately have the greatest impact on education and practice.
\end{abstract}

Key Words: Ethics; Pain competencies; Prelicensure health science students

$\mathrm{U}$ nrelieved acute and persistent pain is a widespread global problem for diverse patient groups across the lifespan. Patients continue to report moderate to severe pain following surgery or trauma (1-3) that may result in a persistent pain problem (4-6). Approximately one in five Canadians report experiencing chronic noncancer pain that impacts their health-related quality of life, which is costly to both patients and the health care system (7-9). Despite worldwide assertions that 'pain management is a human right', statistics indicate that pain continues to be a problem for many individuals $(10,11,12)$. Major gaps exist between evidence and clinical practices, which may reflect traditional beliefs and outdated management approaches (11), revealing a clinical problem with significant ethical dimensions.

\section{L'éthique des compétences canadiennes sur la douleur en début de pratique : comment nous en sortons-nous?}

HISTORIQUE : Même si la douleur non soulagée continue de représenter un problème important, très peu de matière est axée sur la douleur dans les programmes de formation avant l'obtention du permis. Les normes de compétences professionnelles influent énormément sur le programme et peuvent garantir que les étudiants du domaine de la santé possèdent les connaissances et habiletés nécessaires pour gérer la douleur de manière à respecter les normes éthiques professionnelles.

OBJECTIFS : Procéder à une analyse systématique et complète afin de déterminer les compétences liées à la douleur exigées des étudiants du domaine de la santé et de la médecine vétérinaire en début de pratique et examiner le lien entre la présence et l'absence de ces compétences et les grandes compétences éthiques.

MÉTHODOLOGIE : Les chercheurs ont sondé les exigences liées aux connaissances, aux habiletés et au jugement sur la douleur qu'il faut posséder en début de pratique à partir de documents nationaux, provinciaux et territoriaux dans les domaines de la dentisterie, de la médecine, des soins infirmiers, de la pharmacie, de l'ergothérapie, de la physiothérapie, de la psychologie et de la médecine vétérinaire.

RÉSULTATS : La dentisterie comprenait deux compétences sur la douleur et les soins infirmiers, neuf. Les autres documents du domaine de la santé ne contenaient aucune référence à ce sujet. Par contre, les exigences nationales liées aux compétences en médecine vétérinaire, sondées à titre comparatif, contenaient neuf compétences liées à la douleur. Tous ces documents comprenaient des compétences liées à l'éthique.

CONCLUSIONS : L'absence de compétences liées à la douleur a des conséquences sur la progression d'une pratique habile et éthique. Le peu d'attention accordée aux compétences liées à la douleur limite la capacité des professionnels de la santé à soulager la souffrance, à favoriser l'autonomie et à bien utiliser les ressources. Le fait d'influencer les organismes professionnels pour qu'ils accroissent le nombre de compétences liées à la douleur exigées en début de pratique pourrait être la mesure qui aura le plus de répercussions sur la formation et la pratique.

Although education has been identified as a strategy to improve ineffective pain management practices (13), recent evidence reveals the continuing lack of pain content in health science curricula, particularly for prelicensure students $(14,15)$. Comprehensive pain assessment and management are essential to reduce the prevalence and burden of pain, and new strategies involving all heath care professionals are required to support these changes. Research indicates that educational initiatives may be most successful when integrated early in the socialization and educational experience of diverse professionals; negative attitudes reinforced in the undergraduate years are more challenging to change later (16). Despite this evidence, both pain management and interprofessional educational efforts have mainly been targeted toward health professionals after graduation. Therefore,

${ }^{1}$ The Lawrence S Bloomberg Faculty of Nursing; University of Toronto, Toronto, Ontario; ${ }^{2}$ Dalhousie University, Halifax, Nova Scotia; ${ }^{3}$ School

of Nursing, University of British Columbia, Vancouver, British Columbia; ${ }^{4}$ Centre for Aging and Health, University of Regina, Regina,

Saskatchewan; ${ }^{5}$ Interdisciplinary Pain Program, Western University, London, Ontario; 6 Acute Pain Service, Alberta Children's Hospital,

Calgary, Alberta; ${ }^{7}$ Leslie Dan Faculty of Pharmacy, University of Toronto, Toronto, Ontario; ${ }^{8}$ School of Nursing, Memorial University,

St. John's, Newfoundland and Labrador; ${ }^{9}$ IWK Health Centre, Halifax, Nova Scotia

Correspondence: Dr Judy Watt-Watson, The Lawrence S Bloomberg Faculty of Nursing, University of Toronto, 155 College Street, Suite 130 ,

Toronto, Ontario M5T 1P8. Telephone 416-978-2850, fax 416-978-8222, e-mail j.watt.watson@utoronto.ca 
TABLE 1

National documents searched for pain competency requirements

\begin{tabular}{|c|c|}
\hline Profession & Document(s) \\
\hline Dentistry & $\begin{array}{l}\text { National Dental Examining Board of Canada, Competencies for a Beginning Dental Practitioner in Canada } \\
\text { www.ndeb.ca/accredited/competencies }\end{array}$ \\
\hline Medicine & $\begin{array}{l}\text { The Royal College of Physicians and Surgeons of Canada } \\
\text { www.royalcollege.ca/public/resources/aboutcanmeds } \\
\text { rcpsc.medical.org/canmeds/bestpractices/framework_e.pdf } \\
\text { Medical Council of Canada: Objectives for the Qualifying Examination } \\
\text { www.med.mun.ca/ugme/docs/Complete_Objectives-e.pdf } \\
\text { Education Program for the MD Degree (ED) Standard } \\
\text { www.Icme.org/standards_educational\%20programs.pdf } \\
\text { Liaison Committee on Medical Education (website) } \\
\text { www.Icme.org/connections.htm } \\
\text { Association of American Medical Colleges } \\
\text { https://www.aamc.org/about/medicalschools/ }\end{array}$ \\
\hline Nursing & $\begin{array}{l}\text { Canadian Nurses Association (CNA), Canadian Registered Nurses' Examination Competencies } \\
\text { www.cna-aiic.ca/en/becoming-an-rn/rn-exam/competencies/ }\end{array}$ \\
\hline Occupational therapy & $\begin{array}{l}\text { Association of Canadian Occupational Therapy Regulatory Organizations: Essential Competencies of Practice for Occupational Therapists } \\
\text { in Canada (3nd edition) June } 2011 \\
\text { www.coto.org/pdf/Essent_Comp_04.pdf }\end{array}$ \\
\hline Pharmacy & $\begin{array}{l}\text { National Association of Pharmacy Regulatory Authorities: Professional Competencies for Canadian Pharmacists at Entry to Practice } \\
\text { http://napra.ca/pages/Licensing_Registration/Licensing_Program.aspx } \\
\text { Model Standards of Practice for Canadian Pharmacists, March } 2009 \\
\text { http://napra.ca/Content_Files/Files/Model_Standards_of_Prac_for_Cdn_Pharm_March09_Final_b.pdf } \\
\text { Association of Faculties of Pharmacy of Canada - Educational Outcomes for First Professional Degree Programs in Pharmacy } \\
\text { (Entry-to-Practice Pharmacy Programs) in Canada } \\
\text { www.afpc.info/downloads/1/AFPC_Education_Outcomes_AGM_June_2010.pdf } \\
\text { Canadian Council for Accreditation of Pharmacy Programs } \\
\text { Accreditation Standards And Guidelines For The Baccalaureate Degree Program In Pharmacy } 2006 \text { (Revised) } \\
\text { www.ccapp-accredit.ca/site/pdfs/university/CCAPP_accred_standards_degree_2006.pdf }\end{array}$ \\
\hline Physiotherapy & $\begin{array}{l}\text { Canadian Physiotherapy Association: Essential Competencies of Physiotherapists in Canada } \\
\text { www.physiotherapy.ca/getmedia/fe802921-67a2-4e25-a135-158d2a9c0014/Essential-Competency-Profile-2009_EN.pdf.aspx }\end{array}$ \\
\hline Psychology & $\begin{array}{l}\text { Canadian Psychological Association: Mutual Recognition Agreement of Regulatory Bodies for Professional Psychologists in Canada: Core } \\
\text { Competencies } \\
\text { www.cpa.ca/documents/MRA.pdf } \\
\text { Canadian Register of Health Service Providers in Psychology (CRHSPP) } \\
\text { www.crhspp.ca/ }\end{array}$ \\
\hline
\end{tabular}

future educational initiatives need to extend their reach to also include prelicensure health professional students. Competency requirements for licensure can facilitate this process. These include the ethical imperative to relieve suffering, to perform comprehensive pain assessments in all patient populations, to be aware of the physiological and psychological effects of unrelieved pain, and to have knowledge of both pharmacological and nonpharmacological methods of analgesia.

Educational programs for prelicensure health science students have included minimal or no pain content, and students have lacked important pain knowledge at graduation (17). Academic accrediting bodies and professional regulatory bodies strongly shape curricula through the regulations they impose (18). Practice guidelines have significant influence on tomorrow's professionals through their incorporation into teaching models (19). Standards for professional competence delineate important domains of professional practice and directions for learning (20). All health science students are required to acquire professional competencies before becoming licensed by their respective regulatory bodies. These competencies tend to be given high priority by academic administrators and curriculum committees, and determine regulatory licensing requirements.

In a preliminary examination of competencies in selected health science professions, minimal evidence of pain management was found, other than as a symptom to aid in diagnosis (21). Therefore, a more comprehensive examination of prelicensure requirements related to pain competencies is required. The purpose of the present survey was to determine the entry-to-practice competencies related to pain required for key health science students at Canadian universities in national, provincial and territorial documents. As a point of comparison, entryto-practice pain competencies required for veterinary medicine graduates were also surveyed. In addition, an examination of how these pain competencies and their presence and absence in various standards relate to key competencies of an ethical nature within these same documents was explored to analyze the implications of the results.

\section{METHOD}

The term 'competency' was clarified from many definitions in the literature. The following definition of 'competency', chosen for the present survey, summarizes the dimensions in many others:

Professional competence entails an integration of competencies and is not simply a collection of isolated competencies... is the habitual and judicious use of communication, knowledge, technical skills, clinical reasoning, emotions, values and reflection in daily practice for the benefit of the individual and community being served (p. 287) (20) ... involves the integrated knowledge, abilities, skills, judgment and attributes required to practice safely and ethically in a designated role and setting (p. 21) (22)

Entry-to-practice competency requirements related to pain knowledge, skill and/or judgement were surveyed from national documents as well as from any relevant provincial and territorial documents for dentistry, medicine, nursing, pharmacy, occupational therapy, 


\section{TABLE 2}

\section{Entry-to-practice pain competencies of Canadian health science graduates in national documents}

National documents
Dentistry
for a Beginning Dental Practitioner in Canada
Medicine
The Royal College of Physicians and Surgeons of Canada:
CanMEDS 2005 Framework (Key and Enabling
Competencies)
Nursing
Canadian Nurses' Association: Registered Nurse
Examination Competencies 2010
Pain competencies

Specific

\section{Occupational therapy}

2. C 35: Manage patients with orofacial pain and/or dysfunction

No specific references to pain knowledge, assessment or management

\section{Nonspecific}

4.4 Ensure patients receive appropriate end-of-life care

\section{Specific}

1. Professional practice (PP)-2 practises in a manner that recognizes and respects the intrinsic worth of clients (eg, providing privacy, respecting diversity and vulnerabilities, relieving suffering, respecting and fostering cultural expression, appropriately using chemical and physical restraints, accepting a client's report of pain) (CNA, 2008)

2. Changes in Health $(\mathrm{CH})-4$ uses appropriate assessment techniques for data collection (eg, observation, inspection, auscultation, palpation, percussion, selected screening tests, pain scales, interview, consultation, focus group, measuring and monitoring)

3. $\mathrm{CH}-7$ applies knowledge from nursing and other disciplines concerning current health situations (eg, the health care needs of older adults, vulnerable and/or marginalized populations, health promotion and injury prevention, pain prevention and management, end-of-life care, addiction, blood-borne pathogens, traumatic stress syndrome) (Jurisdictional Collaborative Process, 2006)

4. $\mathrm{CH}-9$ identifies actual and potential changes in health (eg, pain management, disability, immobility)

5. $\mathrm{CH}-42$ promotes and maintains comfort (eg, the nurse's presence, warm and cold application, touch, positioning)

6. $\mathrm{CH}-49$ assesses when pro re nata medication is indicated (eg, analgesics, inhalers, antihypertensives, antianginals, laxatives, antianxiety agents)

7. $\mathrm{CH}-51$ assists the client to manage pain with nonpharmacological measures (eg, applying heat and cold, touch, massage, visual imagery, turning and positioning)

8. $\mathrm{CH}-52$ assists the client to manage pain with pharmacological agents or devices (eg, nonopiates, opiates, epidural analgesia, patient-controlled analgesia)

9. $\mathrm{CH}-77$ provides supportive care to clients with chronic health situations (eg, outpatient clinics, adult day care, respite care, pain management, symptom management, polypharmacy, group therapy, addictions counselling)

\section{Nonspecific}

1. $\mathrm{CH}-13$ individualizes the plan of care to apply interventions consistent with the client's capacities, identified priorities and health situation (eg, geriatric care, palliative care)

2. $\mathrm{CH}-71$ provides supportive care to meet hospice, palliative or end-of-life care needs of dying clients (eg, symptom control, spiritual care, advocacy, family counselling, support for clients and significant others, advance care planning, grief and bereavement counselling). (Jurisdictional Collaborative Process, 2006)

No references to pain knowledge, assessment or management

Association of Canadian Occupational Therapy Regulatory

Organizations: Essential Competencies of Practice for

Occupational Therapists in Canada 2003

\section{Pharmacy}

No references to pain knowledge, assessment or management

National Association of Pharmacy Regulatory Authorities:

- Professional Competencies for Canadian Pharmacists at Entry to Practice 2007

- Model Standard of Practice for Canadian Pharmacists 2009

Association of Faculties of Pharmacy of Canada :

- Educational Outcomes for First Professional Degree Programs in Pharmacy (Entry-to-Practice Pharmacy Programs) in Canada

\section{Physical therapy}

No references to pain knowledge, assessment or management

National Physiotherapy Advisory Group: Project Partners

(ACCPAP, CAPR, CPA, CCPUP) 2009

\section{Psychology}

Association of Canadian Regulatory Organizations, Mutual

Recognition Agreement: Core Competencies 2001, 2004:

Practice Guidelines for Providers of Psychology Services 2001

ACCPAP Accreditation Council for Canadian Physiotherapy Academic Programs; CAPR Canadian Alliance of Physiotherapy Regulators; CPA Canadian Physiotherapy Association; CCPUP Canadian Council of Physiotherapy University Programs 


\section{TABLE 3}

Entry-to-practice national nursing pain competencies adapted provincially and territorially

\section{Provincial/territorial \\ adaptation of national \\ documents \\ College of Registered \\ Nurses of British \\ Columbia}

\section{Pain competencies}

22. Has a knowledge base from nursing and other disciplines concerning health care issues (eg, the health care needs of older individuals; vulnerable and/or marginalized populations; health promotion; pain prevention and management; end-of-life care; problematic substance use; blood borne pathogens; mental health issues; and chronic disease management).

73. Applies knowledge consistently when providing care for physiological and psychological needs to prevent development of complications (eg, optimal ventilation and respiration; circulation; fluid and electrolyte balance; pain management; adverse medication effects; nutrition; urinary elimination; bowel elimination; body alignment; mobility; tissue integrity; comfort; delirium; and optimum sensory stimulation).

78. Applies evidence-informed practices of pain prevention and management with clients using pharmacological and nonpharmacological measures.

80. Provides registered nursing care to meet hospice, palliative or end-of-life care needs (eg, pain and symptom control; spiritual support; advocacy; and support for significant others).

College and Association 20. Has a knowledge base from nursing and other disciplines concerning current health care issues (eg, the health care needs of older of Registered Nurses of Alberta individuals, aboriginal health, health promotion, pain prevention and management, end-of-life care, addictions, blood borne pathogens, traumatic stress syndrome and chronic disease management).

74. Applies evidence-informed practices of pain prevention and management with clients in various states of health and illness using pharmacological and nonpharmacological measures.

Hospice Palliative Care All entry-level nursing education programs should have a core hospice, palliative care component that includes pain and symptom Nursing

Saskatchewan Registered Nurses' Association

The College of Registered Nurses of Manitoba

College of Nursing of Ontario

Ordre des infirmières et infirmiers du Québec The Nurses Association of New Brunswick 2005 management, psychosocial support, and grief and bereavement. All registered nurses need education in caring for individuals and families to live even when they are living and dying.

There were no competencies that relate to pain or comfort.

19. Has a knowledge base from nursing, which is informed by other disciplines concerning current health care issues, (eg, the health care needs of older individuals, aboriginal health, health promotion, pain prevention and management, end-of-life care, addictions, blood borne pathogens, persons with disabilities and traumatic stress syndrome).

61. Applies knowledge consistently when providing care for physiological needs to prevent development of complications (eg, optimal ventilation and respiration, circulation, fluid and electrolyte imbalance, nutrition, urinary elimination, bowel elimination, body alignment, mobility, tissue integrity, comfort, sensory stimulation).

73. Applies evidence-informed practices of pain prevention and management with clients in various states of health and illness using pharmacological and nonpharmacological measures.

22. Has a knowledge base from nursing and other disciplines concerning current health care issues (eg, the health care needs of older individuals, vulnerable and/or marginalized populations, health promotion, pain prevention and management, end-of-life care, problematic substance use, blood-borne pathogens and traumatic stress syndrome).

73. Applies knowledge consistently when providing care for physiological needs to prevent development of complications (eg, optimal ventilation and respiration, circulation, fluid and electrolyte balance, nutrition, urination elimination, bowel elimination, body alignment, mobility, tissue integrity, comfort and sensory stimulation).

78. Applies evidence-informed practices of pain prevention and management with clients using pharmacological and nonpharmacological measures.

80. Provides nursing care to meet hospice, palliative or end-of-life care needs (eg, pain and symptom control, spiritual support, advocacy, support for significant others).

http://www.oiiq.org/

22. Has a knowledge base from nursing and other disciplines concerning current health care issues (eg, the health care needs of older individuals, vulnerable and/or marginalized populations, health promotion, pain prevention and management, end-of-life care, problematic substance use, blood-borne pathogens and traumatic stress syndrome).

73. Applies knowledge consistently when providing care for physiological needs to prevent development of complications (eg, optimal ventilation and respiration, circulation, fluid and electrolyte balance, nutrition, urinary elimination, bowel elimination, body alignment, mobility, tissue integrity, comfort and sensory stimulation).

78. Applies evidence-informed practices of pain prevention and management with clients using pharmacological and nonpharmacological measures.

80. Provides nursing care to meet hospice, palliative or end-of-life care needs (eg, pain and symptom control, spiritual support, advocacy, support for significant others). 
TABLE 3 - CONTINUED

Entry-to-practice national nursing pain competencies adapted provincially and territorially

Provincial/territorial

adaptation of national

documents

Pain competencies

College of Registered 22. Has a knowledge base from nursing and other disciplines concerning current health care issues (eg, the health care needs of older

Nurses of Nova Scotia individuals, vulnerable and/or marginalized populations, health promotion, pain prevention and management, end-of-life care, problematic substance use, blood borne pathogens and post-traumatic stress syndrome).

77. Applies knowledge consistently when providing care for physiological needs to prevent development of complications (eg, optimal ventilation and respiration, circulation, fluid and electrolyte balance, nutrition, urinary elimination, bowel elimination, body alignment, mobility, tissue integrity, comfort, sensory stimulation).

82. Applies evidence-informed practices of pain prevention and management with clients using pharmacological and nonpharmacological measures (eg, relaxation, distraction, traditional practices).

84. Provides nursing care to meet hospice, palliative or end-of-life care needs (eg, pain and symptom control, spiritual support, advocacy, support for significant others).

Association of

Registered Nurses of Newfoundland and Labrador

22. Has a knowledge base from nursing and other disciplines concerning current health care issues (eg, the health care needs of older individuals, vulnerable and/or marginalized populations, health promotion, pain prevention and management, end-of-life care, problematic substance use, blood borne pathogens, and traumatic stress syndrome).

73. Applies knowledge consistently when providing care for physiological needs to prevent development of complications (eg, optimal ventilation and respiration, circulation, fluid and electrolyte balance, nutrition, urinary elimination, bowel elimination, body alignment, mobility, tissue integrity, comfort, sensory stimulation)

78. Applies evidence-informed practices of pain prevention and management with clients using pharmacological and nonpharmacological measures.

80. Provides nursing care to meet hospice, palliative or end-of-life care needs (eg, pain and symptom control, spiritual support, advocacy, support for significant others).

The Registered Nurses Association of the Northwest Territories and Nunavut

22. Has a knowledge base from nursing and other disciplines concerning current health care issues (eg, the health care needs of older individuals, vulnerable and/or marginalized populations, health promotion, pain prevention and management, end-of-life care, problematic substance use, blood-borne pathogens and traumatic stress syndrome).

73. Applies knowledge consistently when providing care for physiological needs to prevent development of complications (eg, optimal ventilation and respiration, circulation, fluid and electrolyte balance, nutrition, urinary elimination, bowel elimination, body alignment, mobility, tissue integrity, comfort, sensory stimulation)

78. Applies evidence-informed practices of pain prevention and management with clients using pharmacological and nonpharmacological measures.

80. Provides nursing care to meet hospice, palliative or end-of-life care needs (eg, pain and symptom control, spiritual support, advocacy, and support for significant others).

physiotherapy, psychology and veterinary medicine. The comprehensiveness of the search was validated with confirmation of website sources by the coauthors, representing pain expertise across Canada in these professions.

\section{RESULTS}

\section{Health sciences}

Document inclusions: National competency or standards documents were examined for dentistry, medicine, nursing, occupational therapy, pharmacy, physical therapy and psychology (Table 1).

National documents: Pain competency statements were found for dentistry and nursing. No references to competencies related to pain knowledge, assessment or management were found in the remaining health science documents (Table 2). While the Royal College of Physicians and Surgeons of Canada CanMEDS document was specifically developed for postgraduate training, no standardized competency documents for prelicensure medical students were found. The CanMEDS competency-based framework describes the core knowledge, skills and abilities of specialist physicians; the extent to which they are officially used in prelicensure curricula or as a basis for their competency development is not known, hence their inclusion here. Moreover, format and terminology from the CanMEDs model were used in developing the prelicensure educational outcomes for pharmacy (p. 6) (24) (Table 1). While pain management and palliative care were listed as topics in the Educational Program for the MD Degree (ED) Standard (p 20-ED10) (Table 1) and pain was listed under etiology for conditions, such as ear pain, in the Medical Council of Canada (Table 1), they were not linked with related competencies. Dentistry included two pain competencies related to orofacial pain and procedural anaesthesia. Nursing included a total of nine specific pain competencies related to pain assessment (Professional Practice [PP]-2, Changes in Health [CH] 4) and management (CH 7, 9, 42, 49, $51,52,77)$ and two nonspecific pain competencies related to palliative and/or end-of-life care needs (CH 13, 71).

Provincial and territorial documents: Provincial and territorial documents referred to and cited only the national pain competency documents for six of the seven professions surveyed. The exception was nursing, with documents from provincial and territorial professional associations referring not only to the national Canadian Nurses Association document, but also including pain-related competencies adapted for emphasis or relevance at their own sites (Table 3). The latter mainly reflected Canadian Nurses Association statements related to $\mathrm{CH}$ concerning pain assessment, management, and palliative care (CH 7, 51, 52 and/or 71).

\section{Veterinary medicine}

The national requirements for veterinary medicine outlined in the Ontario Veterinary College Professional Competencies of Canadian Veterinarians (23) listed 10 pain-related competencies. Nine competencies were related to analgesic and anaesthetic management, and one additional competency was related to alleviating suffering (Table 4).

\section{DISCUSSION}

These data indicate that a baseline understanding of knowledge, skills and judgement related to pain assessment and management is not recognized as a priority in most of the seven health science documents surveyed. Although a total of 11 entry-to-practice pain-related 


\section{TABLE 4 \\ Entry-to-practice pain competencies of Canadian veterinarians (23)}

V6.16: Recognize when analgesia and anaesthesia are warranted and implement effective techniques

Effective analgesia/anaesthesia is implemented when warranted, with minimum risk (p. 23).

Graduates will be able to:

- Recognize the need for analgesia and/or anaesthesia, using prevailing standards appropriate to the circumstances.

- Identify options for analgesic and/or anaesthetic techniques.

- Identify and discuss with the client, to an appropriate extent, the risks associated with particular anaesthetic and/or analgesic options.

- Adopt and implement tenable procedures.

- Observe ethical and statutory obligations.

- Anticipate and take steps to prevent untoward sequelae.

- Monitor results and adapt techniques according to need.

- Deal with emergencies effectively.

- Take steps to ensure safe and humane recoveries.

Analgesia:

- Pain prediction and diagnosis, cold therapy, pharmacological analgesia (including NSAIDs, corticosteroids, opioids).

- Monitoring: visual/manual collection of parameters.

- Risk identification and reduction (due to age, size, temperament, recumbency, disease/drug interactions)

V6.6c: Implement appropriate and effective emergency measures, and/or alleviate suffering.

NSAID Nonsteroidal anti-inflammatory drug

competencies are listed for nursing and two for dentistry, other disciplines do not include specific expectations in this area. The consequences of this are dire. For example, pain is often underassessed and undertreated (6); this is especially true in special populations such as residents of long-term care facilities (25). Inadequate pain education in staff is recognized as a significant barrier to effective assessment and management (26). Moreover, even when pain assessment information is available to health professionals, they appear not to use it in their treatment planning (27), reinforcing the need for pain education at the prelicensure level.

In contrast to the limited pain education for health professionals working with humans, pain competencies for graduates from veterinary colleges are specific to pain assessment and management and offer clear criteria for evaluating knowledge, skills and judgement as they move into their professional practice. While a national consensus for each profession is essential, it is interesting that nursing organizations in seven provinces and one territory adapted key competencies relevant to their constituents. Moreover, of all the health professions surveyed, nursing has made the most progress in the area of professional competencies both at the national and provincial/territorial levels (21).

Prelicensure pain education is a critical step in ensuring that health care practitioners entering the workforce are competent in pain management. However, in a survey of pain curricula in major Canadian health science faculties, only one-third could identify designated pain content hours in their prelicensure curricula (15). Despite the availability of internationally accepted core and discipline-specific curricula (28), the majority of health science faculties or departments $(67.5 \%)$ were unable to delineate the actual hours allotted to teaching pain content in their curriculum, including clinical practice placements. Where pain was mentioned, it was identified only as a symptom to aid in diagnosis, and not as an entity requiring assessment and management in its own right. Although the need for interprofessional pain education was expressed, this has yet to be included in the curricula for most respondents. The lack of common pain knowledge, language and management strategies is also a concern because no single professional will be able to solve this problem. Health professionals need to be taught not only about the prevalence and consequences of pain, but also how to work together to diminish it.

Curricula are shaped by academic accrediting and professional regulatory bodies through the regulations they impose. Students must acquire the necessary professional competencies to become licensed by their respective regulatory bodies. However, a previous survey demonstrated that minimal to no pain-related entry-to-practice competencies are required for Canadian health science students (21). Both previous and current data indicate that a baseline understanding of pain assessment and management knowledge, skills and judgement is not recognized as a priority in the documents of most of the Health Science disciplines surveyed. The competencies tended not to be specific to pain assessment and management nor to offer clear criteria for evaluating knowledge, skills and judgement. For example, the highly respected CanMEDS 2005 Framework (29) includes key and enabling competencies that relate to seven roles that physicians are expected to perform. These include medical expert as the central one, communicator, collaborator, manager, health advocate, scholar and professional. Despite pain being a very common patient symptom in medical practice, pain is not mentioned, nor is it clear whether "enhancing quality care and patient safety" includes pain assessment and management (2.4, p. 2) (29). Similarly, in pharmacy, "patient care competencies" include attention to adverse drug reactions $(1.2 .11$, p. 70$)$ and potential drug therapy problems, such as drug abuse (1.5.vii), that are not specific to pain (24).

The Canadian Patient Safety Institute has identified six domains to enhance patient safety across the health professions (30). The fourth domain refers to anticipating, recognizing and managing situations that place patients at risk to improve outcomes for patients and their families by preventing or mitigating adverse effects (p. 17). One of the elements of this domain is safe administration of analgesics and the standardization of approaches and procedures such as evidenceinformed practice guidelines. Where do clinicians learn these, if not as a basis for practices in their prelicensure curriculum? The prevalence of inadequate pain management indicates that these are not necessarily learned later in the practice setting.

Evidence is mounting that unrelieved intense noxious stimuli, such as unrelieved pain after surgery, can result in long-term persistent pain for $10 \%$ to $50 \%$ of individuals after common surgeries (4). Unrelieved significant pain is a safety issue that needs to be recognized in current education and management practices. Moreover, an inadequate understanding and demonstration of pain competencies can have an impact on the potential capacity for health care professionals to practise ethically (31).

\section{The inseparability of ethics}

All national competency/standard documents for all health professionals include competencies pertaining to ethics. For example, a key competency of a pharmacist is to "demonstrate professional integrity and act to uphold professional integrity and act to uphold professional standards of practice and codes of ethics" (number 3 [24]); a physician must have the ability "to demonstrate a commitment to their patients, profession, and society through ethical practice", which is enabled by the ability to "exhibit appropriate professional behaviours in practice, including honesty, integrity, commitment, compassion, respect, and altruism" (p. 8) (29). This type of language is consistent with that of dentistry competencies that state that a dentist must "apply accepted principles of ethics and jurisprudence to maintain standards and advance knowledge and skills" (number 45) (32), and the nursing statement that the registered nurse "practises in a manner consistent with the values in the Code of Ethics for Registered Nurses (eg, providing safe, compassionate, competent and ethical care; promoting health and well-being; promoting and respecting informed decision-making; preserving dignity; maintaining privacy and confidentiality; promoting justice; being accountable)" (33). Analogous ethical principles and standards have also been adopted by the Canadian Psychological Association (34), the Canadian Association of Occupational Therapists (35) and the Canadian Physiotherapy Association (36). 
A health professional's capacity to be ethical does not fit easily into a series of isolated competencies because the knowledge, skills and judgement of ethics are generally only measurable and observable when they are manifested through the provision of clinical care that involves other clinical competencies, such as developing a plan of care with a patient and family or administering a treatment. In other words, ethical competencies do not stand alone, but are integral to all competencies. Margaret Urban Walker (37), a theorist in ethics, argues that morality is not socially modular, in that moral practices cannot be disentangled from other social practices. Accordingly, the social practices constitutive of clinical competencies are an expression of the moral agency of health professionals.

Given the inextricable nature of ethical and other competencies, the lack of competencies related to pain assessment and management has implications for advancing the ethical practice of health professionals. The lack of attention to and demonstration of sufficient pain competencies limits the potential capacity for health care professionals to practise ethically. For example, to demonstrate compassion would entail both the capacity to perceive the pain and suffering of a patient and to relieve that pain when possible. Pain assessment skills are an aspect of this perception that distinguishes the potential to demonstrate a fully compassionate, skilled assessment of pain instead of a commonplace perception. For example, a lay person may not have the skill and knowledge to be as sensitive to the complexity of pain because pain can be expressed in multiple ways as a result of age, culture, type of illness and previous pain experiences. It may not be readily obvious that someone could be experiencing severe pain without well-honed pain assessment competencies. Managing the patient's pain, a response that reflects an outward expression of compassion, requires that a health professional have a range of pain competencies that involve knowledge and skills related to pharmacological and nonpharmacological interventions. Here again, the lack of attention to pain competencies limits the capacity of a health professional to practise ethically, in that he/she cannot be fully compassionate.

It is intriguing that veterinary medicine has such a comprehensive list of competencies related to pain, including one that is explicitly related to the responsibility to 'alleviate suffering' in an emergency situation. In part, this may reflect the widespread moral acceptance of the practice of euthanasia when caring for animals, but it also may be that compassion, with its concomitant perceptions and actions, is more easily realized when we are caring for animals. Freud (38) spoke of "affection without ambivalence," and a "feeling of an intimate affinity, of an undisputed solidarity" in reference to his dog, Jofi. It may be that we need to reflect on the ideals of animal care when we create competencies and provide care to humans to keep in check the ambivalence we experience for other humans, which can limit our compassion. We do not expect animals to deceive us about pain and do not approach an animal in pain in the way that we subtly approach humans in pain, ie, with an almost innate scepticism.

Fostering patient autonomy and decisionmaking can also be limited by the lack of pain assessment and management competencies. Pain and illness can constrain a patient's capacity to be actively involved in decisionmaking regarding their treatments and other matters. A failure to manage pain well can limit a meaningful capacity to provide information to a patient "in such a way that it is understandable, encourages discussion, and participation in decision-making" (29). The meaningful provision of information does not only involve the ability of the health professional to explain clearly and fully. It also requires the recipient of the information, the patient and family, to be able to receive the information to the greatest extent possible. Relieving pain can facilitate this receptive ability tremendously.

The failure to prepare future health care professionals sufficiently to respond to pain also has implications for the just and prudent use of resources. For example, a physician must "recognize the importance of just allocation of health care resources, balancing effectiveness, efficiency, and access with optimal patient care" (section 3.1) (29) and "apply evidence and management processes for cost-appropriate care" (section 3.2) (29). While it is clear that uncontrolled pain is harmful to individuals, it is also harmful to society more generally, especially economically, because resources could be used much more effectively and competently. Inadequate acute pain control postsurgically can lead to emergency room visits and readmission to hospital, which could be avoided. Unfortunately, it can also lead to chronic pain, which is associated with increased usage of health care resources, decreased productivity and increased disability (11). In Canada it is estimated that the annual direct cost per chronic pain sufferer is approximately $\$ 3,500$, resulting in an overall cost to the system of $\$ 400$ million. The indirect costs of chronic pain are difficult to measure but include the consequences of disability, work absence, uninsured treatments and informal care (39). It is critical that health care professionals have the competencies necessary to provide evidence-based care to manage and prevent chronic pain.

\section{CONCLUSION}

Unrelieved pain, whether acute, intermittent or persistent, is a very prevalent and costly problem for Canadians and individuals worldwide. Continuing research points to a gap between evidence and clinical practices that results in outdated management approaches and ineffective care outcomes. Although pain education is a strategy to improve ineffective pain management practices, pain content is minimal in prelicensure health science curricula. Entry-level competencies for these students need to be sufficiently grounded in practice to provide accurate and adequate descriptions to guide curricula and regulation. Standards for professional competence delineate important domains of professional practice and direction for learning (28) that have both safety and ethical implications. While the accreditation of academic programs is national, schools must adhere to provincial and territorial standards. Competencies are often set at both levels, although at times they are shared, making it important to lobby professional bodies at all levels to increase the number of required entry-topractice competencies. Influencing these professional bodies may ultimately have the greatest impact on curricula. The recognition of the inseparability of competencies in pain and ethics may add an additional impetus to add pain competencies to professional standards to make possible the full realization of ethical competencies. Graduates from veterinary colleges should not have more pain management skills than graduates from our health science faculties.

ACKNOWLEDGEMENTS: The present work was supported by funding from the Canadian Pain Society. The authors thank Katye Stevens and Jaime Lapeyre for their assistance with the project.

\section{REFERENCES}

1. Aasvang E, Gmaehle E, Hansen J, et al. Predictive risk factors for persistent postherniotomy pain. Anaesthesiology 2010;112:957-69

2. Schug S. 2011: The global year against acute pain. Anaesth Intensive Care 2011;39:11-4.

3. Watt-Watson J, Stevens B, Katz J, Costello J, Reid D, David T. Impact of a pain education intervention on postoperative pain management. Pain 2004;9:73-85

4. Kehlet H, Jensen TS, Woolf CJ. Persistent postsurgical pain: Risk factors and prevention. Lancet 2006;367:1618-25

5. Andersen K, Kehlet H. Persistent pain after breast cancer treatment: A critical review of risk factors and strategies for prevention. J Pain 2011;12:725-46.

6. Watt-Watson J, Choinière M, Costello J, et al. Prevalence characteristics and risk factors of persistent post-operative pain after cardiac surgery. The 13th International Association for the Study of Pain Congress Proceedings; August 29 to September 2, 2010, Montreal, Quebec.

7. Choinière $\mathrm{M}$, Dion $\mathrm{D}$, Peng $\mathrm{P}$, et al. The Canadian STOP-PAIN project - Part 1: Who are the patients on the waitlists of multidisciplinary pain treatment facilities? Can J Anaesth 2010;57:539-48.

8. Moulin DE, Clark AJ, Speechley M, Morley-Forster PK.

Chronic pain in Canada - prevalence, treatment, impact and the role of opioid analgesia. Pain Res Manag 2002;7:179-84. 
9. Boulanger A, Clark AJ, Squire P, Cui E, Horbay GL. Chronic pain in Canada: Have we improved our management of chronic noncancer pain? Pain Res Manag 2007;12:39-47.

10. Brennan F, Carr D, Cousins M. Pain management: A fundamental human right. Anaesthes Analg 2007;105:1;205-21.

11. Lynch M. The need for a Canadian pain strategy. Pain Res Manag 2011;16:77-80.

12. Schug S. 2011-The global year against acute pain. Anaesth Intensive Care 2011;39:11-4

13. Sessle B. Incoming President's address: Looking back, looking forward. In: Devor M, Rowbotham MC, Wisenfield-Hallin Z, eds. Progress in Pain Research and Management, Proceedings of the 9th World Congress on Pain; Aug 22-27 1999; Vienna, Austria. Seattle: IASP Press, 2000;16:9-18.

14. Briggs E, Carr ECJ, Whittaker M. Survey of undergraduate pain curricula for healthcare professionals in the United Kingdom. Eur J Pain 2011;15:789-95.

15. Watt-Watson J, McGillion M, Hunter J, et al. A survey of prelicensure pain curricula in health science faculties in Canadian universities. Pain Res Manag 2009;14:439-44.

16. Barr H, Freeth D, Hammick M, Koppel I, Reeves S. Evaluations of Interprofessional Education: A United Kingdom Review for Health and Social Care. London: United Kingdom Centre for the Advancement of Interprofessional Education with the British Educational Research Association, 2000.

17. Watt-Watson J, Hunter J, Pennefather P, et al. An integrated undergraduate curriculum, based on IASP curricula, for six health science faculties. Pain 2004;110:140-8.

18. Peter E, Watt-Watson J. Improving pain management education. In: Rashiq S, Schopflocher D, Taenzer P, E, eds. Chronic Pain: A Health Policy Perspective. Weinheim: Wiley-VCH Verlag GmbH \& Co. KgaA, 2008:255-64.

19. Canadian Psychological Association: Mutual Recognition Agreement of Regulatory Bodies for Professional Psychologists in Canada: Core Competencies. < www.cpa.ca/documents/MRA.pdf > (Accessed December 27, 2011).

20. Epstein R, Hundert E. Defining and assessing professional competence. JAMA 2002;287:226-35.

21. Watt-Watson J, Peter E, Hayward M, Carlsson L. Entry to practice pain competencies: Survey of requirements for health science students. Canadian Pain Society Annual Conference; May 28 to 30, 2008; Victoria, British Columbia; Pain Res Manag 2008;13:111-53.

22. CNO 2008, College of Nurses of Ontario, National Competencies in the context of entry-level Registered Nurse practice. <www.cno.org/Global/docs/reg/41037_EntryToPracitic_final.pdf> (Accessed December 4, 2011).

23. Ontario Veterinary College Professional Competencies of Canadian Veterinarians: A Basis for Curriculum Development <www.ovc.uoguelph.ca/academics/dvm2000/compet.pdf> (Accessed December 4, 2011).

24. National Association of Pharmacy Regulatory Authorities: Professional Competencies for Canadian Pharmacists at Entry to
Practice. $<$ http://napra.ca/pages/Licensing_Registration/Licensing_ Program.aspx > (Accessed December 27, 2011).

25. Hadjistavropoulos T, Marchildon G, Fine P, et al. Transforming long-term care pain management in North America: The policy clinical interface. Pain Med 2009;10:506-20.

26. Kaasalainen S, Coker E, Dolovich L, et al. Pain management decision-making among long-term care physicians and nurses. West J Nurs Res 2007;29:561-80.

27. Hadjistavropoulos T, MacNab YC, Lints-Martindale AC, Martin R, Hadjistavropoulos $\mathrm{H}$. Does routine pain assessment result in better care? Pain Res Manag 2009;14:211-6.

28. International Association for the Study of Pain. Curricula. $<$ www.iasp-pain.org/AM/Template. $\mathrm{fm}$ ?Section=Curricula\&Template $=/ \mathrm{CM} /$ HTMLDisplay. cfm\&ContentID=1952> (Accessed December 4, 2011).

29. CanMEDS: Physician Competency Framework. <www.royalcollege. ca/public/resources/aboutcanmeds> (Accessed December 4, 2011).

30. Canadian Patient Safety Institute. The Safety Competencies. <www. patientsafetyinstitute.ca/English/toolsResources/safetyCompetencies/ Pages/default.aspx > (Accessed December 4, 2011).

31. Malloy DC, Williams J, Hadjistavropoulos T, et al. Ethical decisionmaking about older adults and moral intensity: An international study of physicians. J Med Ethics 2008;34:285-96.

32. National Dental Examining Board of Canada, Competencies for a Beginning Dental Practitioner in Canada. <www.ndeb.ca/ accredited/competencies> (Accessed December 27, 2011).

33. CNA: Code of Ethics for Registered Nurses, $2010<$ www.cna-aiic. $\mathrm{ca} / \mathrm{en} /$ becoming-an-rn/rn-exam/competencies/> (Accessed December 4, 2011).

34. Canadian Psychological Association. Canadian Code of Ethics for Psychologists, 3rd edition, 2000. <www.cpa.ca/cpasite/userfiles/ Documents/Canadian\%20Code\%20of\%20Ethics\%20for\%20Psycho. pdf $>$ (Accessed December 27, 2011).

35. Canadian Association of Occupational Therapists, Canadian Association of Occupational Therapists, 2007. <www.caot.ca/ default.asp?pageid=35> (Accessed December 27, 2011).

36. Canadian Physiotherapy Association, Code of Ethics: Rules of Ethics, 2003. <www.physiotherapy.ca/getmedia/fe802921-67a24e25-a135-158d2a9c0014/Essential-Competency-Profile-2009_ EN.pdf.aspx > (Accessed December 27, 2011)

37. Walker MU. Moral Understandings: A Feminist Study in Ethics. New York: Routledge, 1998.

38. Freud S. Letter from Sigmund Freud to Marie Bonaparte, December 6, 1936. Letters of Sigmund Freud 1873-1939, 1936; 434-435. <www.pep-web.org/document.php?id=zbk.051.0434a> (Accessed December 27, 2011).

39. Phillips CJ, Schopflocher D. The economics of pain. In: Rashiq S, Schopflocher D, Taenzer P, Jonsson E, eds. Chronic Pain: A Health Policy Perspective. Weinheim: WILEY-VCH Verlag GmbH \& Co. KgaA, 2008:41-50. 


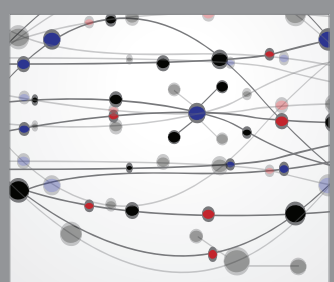

The Scientific World Journal
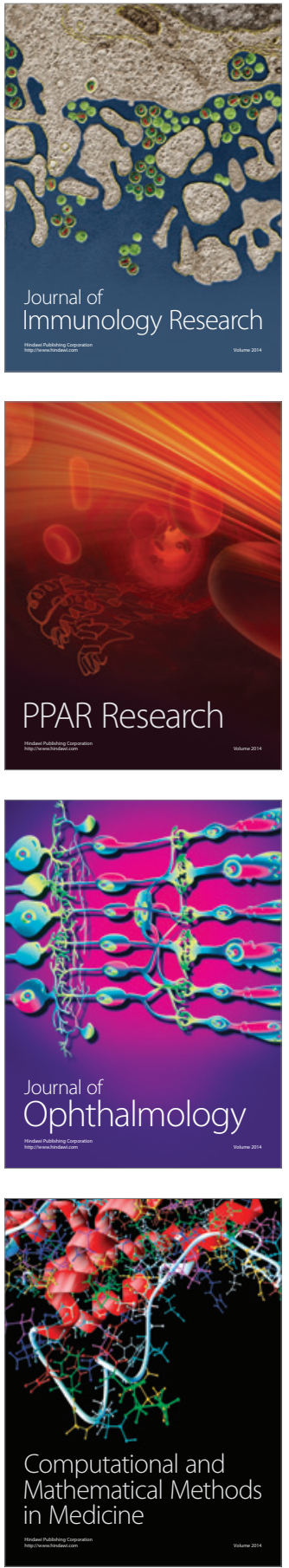

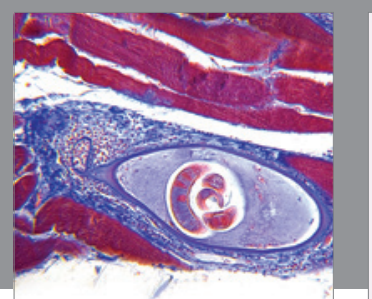

Gastroenterology Research and Practice

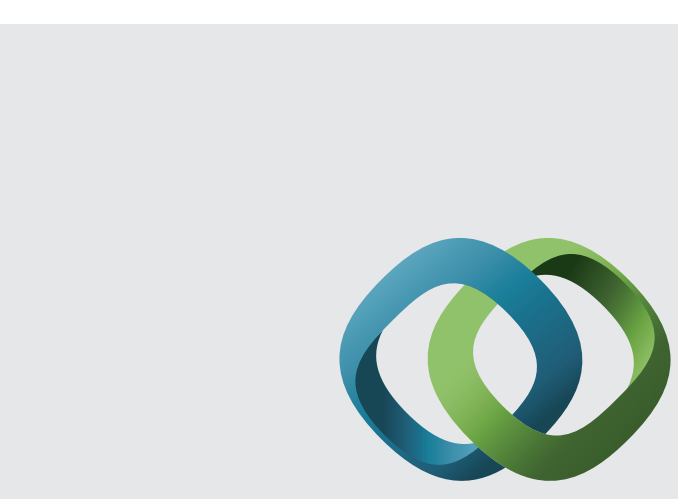

\section{Hindawi}

Submit your manuscripts at

http://www.hindawi.com
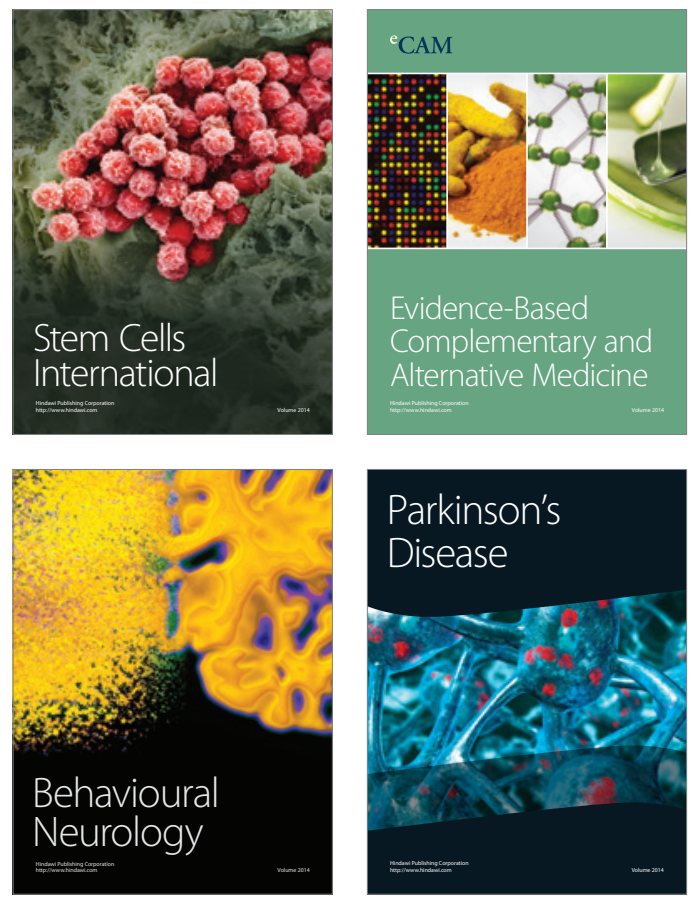
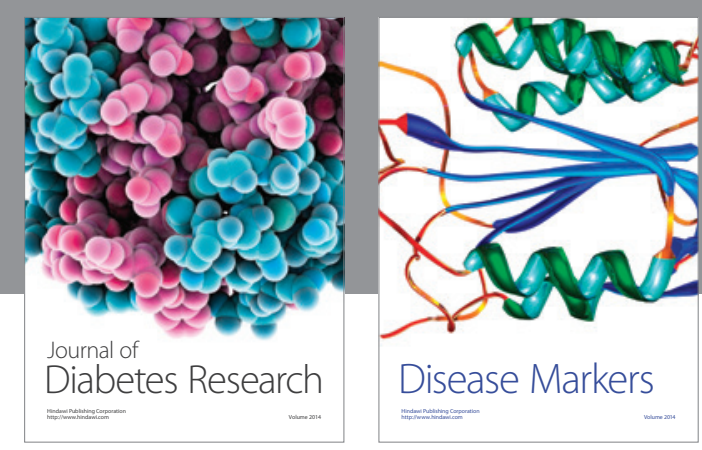

Disease Markers
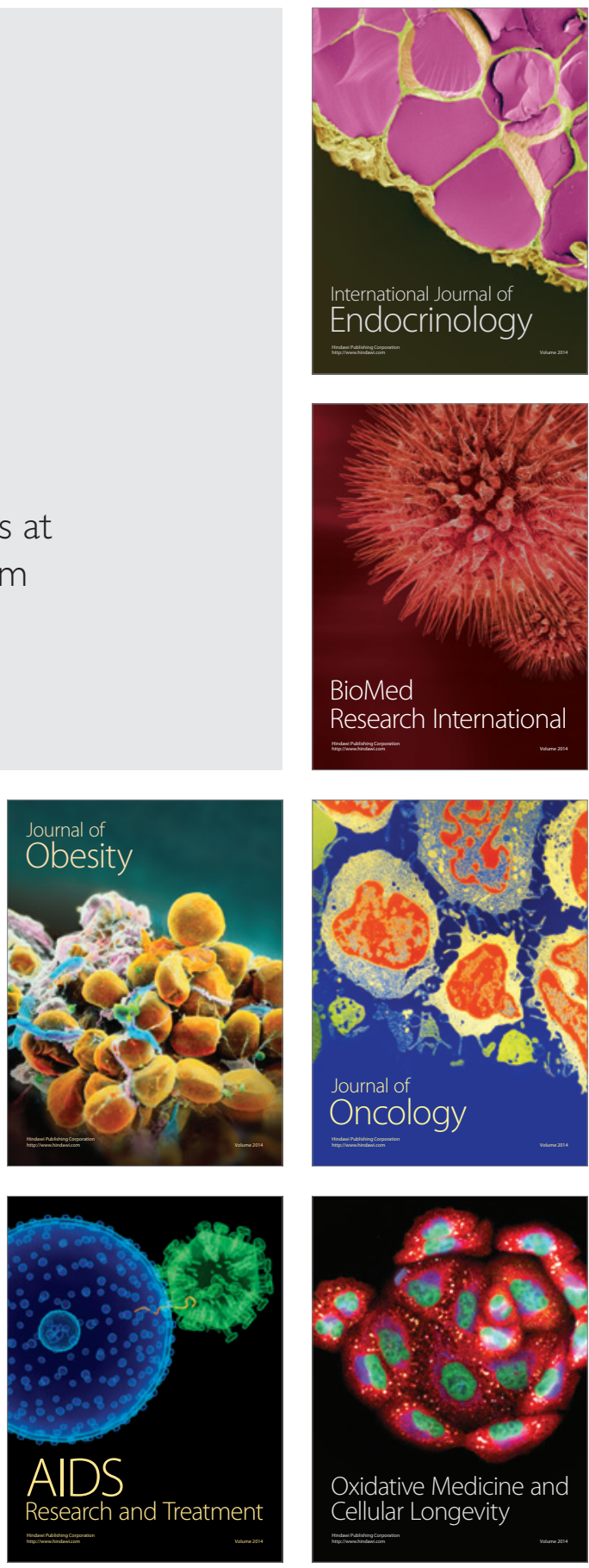